\title{
Editorial
}

Dermatology

Published online: June 26, 2010

\section{Interleukin 4 or Cytokine Antagonists? Time to Change the Search for Novel Psoriasis Therapies}

\author{
Martin Röcken \\ Department of Dermatology, University Medical School of Tübingen, Eberhard Karls University Tübingen, \\ Tübingen, Germany
}

\section{Changing Psoriasis Therapy}

The treatment of psoriasis has been revolutionized over the past 20 years. Psoriasis was one of the psychologically most stressful diseases of mankind. The life of patients with psoriasis has changed in 2 major, consecutive steps, first with the introduction of photochemotherapy and methotrexate in the 1970s [1]. These were the first efficient outpatient treatments for plaque-type psoriasis and remain a key stone in treating psoriasis $[2,3]$, even though photochemotherapy is time-consuming. Dosing and longterm safety of methotrexate remained questionable until recently; methotrexate is now one of the most efficient therapies with excellent long-term safety data and serves as standard for most psoriasis studies [3-7]. The introduction of fumarates in a few countries during the 1990s $[7,8]$ and, since 2000 , the establishment of therapies with either tumor necrosis factor (TNF) or interleukin-12/23 (IL-12/23) antagonists $[4-7,9]$ were the second step dramatically improving the life of patients with psoriasis.

Besides methotrexate, fumarates are a second therapy that is believed to improve psoriasis without dramatically increasing the risk of skin cancer, severe infections or major metabolic disorders $[8,10]$. The central benefit of cytokine antagonists are psoriasis variants that are largely resistant to conventional therapies, namely psoriasis arthritis or Hallopeau-type psoriasis [4-7, 9].

\section{Limitations of Modern Psoriasis Therapy}

Yet, there are limitations, beyond the excessive pricing that became popular with the new compounds: TNF is strictly required for the control of bacterial and fungal infections by neutrophils and for granuloma formation in order to control infections with mycobacteria and many other pathogens [3-7]. The role of TNF antagonists in viral diseases and human cancer remains under debate [11]. IL-12 is a key cytokine for interferon-dependent defense mechanisms, such as viral diseases, probably cancer, and again granuloma formation such as mycobacterial infections $[9,12,13]$. Moreover, cytokine antagonists may lose their efficiency; after about 1 year TNF antagonists remain effective in about $60 \%$ of patients, and the long-term effects and side effects ( $>10$ years) remain to be established. The difficulty in truly estimating the biology of cytokine antagonists is underlined by simple clinical observations: all TNF antagonists were developed with similar rational approaches. Clinical studies revealed that the effects of the various TNF antagonists on the various types of psoriasis, psoriasis arthritis, rheumatoid arthritis or inflammatory bowel disease differ strongly between these compounds - for unknown reasons [3-7]. 


\section{Requirements for Novel Psoriasis Therapies}

As psoriasis is basically a disease resulting from an enhanced inflammatory immune response, any currently available anti-psoriasis therapy will be immunosuppressive, as long as we basically ignore the antigens involved. Therapies should educate selectively the 'inflammationinducing T cells', independently of the antigen involved.

With the therapies currently available, it is mandatory to look for entirely novel immunosuppressive approaches: such therapies should help patients not responding to either one of the therapies, should have a short half-life in order to make the treatment more manageable in the case of intercurrent infections and, if possible, rather decrease than increase the risk of cancer and severe infections. Treatment with IL-4 might be such an approach $[14,15]$.

In this issue Zhang et al. [16] show that topical application of a plasmid encoding the IL-4 gene allows transdermal delivery of IL-4 and strongly improves skin inflammation in a model disease that closely mimicks psoriasis [17]. In this model, mice express the gene for the vascular endothelial growth factor in the basal keratinocytes. In response to an inflammatory trigger, these mice develop a skin inflammation with hyperparakeratosis, papillomatosis and papillar angiogenesis, neutrophil influx and expression of the inflammation-associated marker that are observed in psoriasis [17]. Zhang et al. now show that topical application of the IL-4-encoding plasmid in a newly designed package allows transdermal application of the IL- 4 gene and intradermal production of IL-4 in quantities that are sufficient to normalize all parameters of inflammation determined and to normalize the skin. This is an important finding as previous studies revealed that IL- 4 has unique anti-inflammatory properties and lacks many of the potential risks of cytokine antagonists.

IL-4 is a highly interesting therapeutic approach for several reasons. Besides the cytokine antagonists currently available, IL-4 is the only biologic that has been shown to improve psoriasis in a clinical phase I/II trial in patients with severe psoriasis. IL- 4 improved psoriasis by about $75 \%$ within 6 weeks, suggesting that IL- 4 therapy would be at least as efficient as the most effective TNF or IL-12/23 antagonists [3-5, 14]. Importantly IL-4 has only a very short half-life and was efficient in all animal models of Th1/17-mediated inflammation tested [15], including experimental diseases like allergic encephalitis [18], contact hypersensitivity [19], psoriasis [20] and many others. There is ample clinical experience with IL-4 in humans, as IL-4 was analyzed for years in cancer patients [21]. A major concern that IL-4 therapy shares with any other immunosuppressive therapy is that it might promote cancer [11] or infectious diseases [12] as TNF or IL12/23 antagonists.

As IL-4 was studied for almost a decade as a therapy for metastatic cancer, it became clear that IL-4 provides no major benefit but, importantly, causes no harm for cancer patients either [21]. Similarly, it is currently unlikely that IL-4 therapy establishes a major risk for new viral or mycobacterial infections as IL-4 strongly stimulates antigen-presenting cells, dendritic cells and macrophages to fight newly invading pathogens $[12,13]$.

However, why is IL-4 efficient in treating psoriasis? Among all cytokines and chemokines known, IL-4 is unique with its effect on CD4+ T helper cells (Th cells). Under normal conditions, activation of Th cells in the context of infection results in IFN- $\gamma$-producing Th1 cells or IL-17-producing Th17 cells. These Th1 and Th17 cells are armed to protect us against most intracellular pathogens. The above-mentioned 'paradoxical' protection mediated by IL- 4 against cancer and newly invading pathogens is beyond the scope of this commentary [for details see 12].

While under normal conditions, activation of Th cells results in Th1 or Th17 cells, priming of Th cells in the presence of either endogenous or exogenous IL-4 leads to a Th2 phenotype that is characterized by the production of IL-4 and strongly suppresses inflammation such as psoriasis in humans $[14,22]$, probably also multiple sclerosis and all experimental inflammatory diseases studied so far under in vivo conditions $[15,16,18,19]$. This is also the case in humans, as shown first in vitro and then in vivo [14, 22]. Indeed, systemic IL-4 therapy at conditions that induce a Th2 phenotype in human Th cells in vitro also induces an IL-4-producing Th2 phenotype in vivo. This in vivo induction of Th2 cells strongly improved the psoriasis, most likely by selectively deviating the psoriasis-causing Th cells into a Th2 phenotype. In agreement with the data available from experimental animals, in humans IL- 4 therapy induces a Th2 phenotype only in currently activated T cells. IL-4 has no known immunosuppressive effect on either naive or resting memory Th cells [14]. Thus, while being highly effective in autoimmune diseases, IL- 4 therapy should be devoid of the broad immunosuppressive effects associated with all other psoriasis therapies available and currently under development.

Where to go for further development of psoriasis therapies? The mainstream currently favors new interesting anticytokine therapies like anti-IL-17 or anti-IL-23p19 antibodies. Yet, no cytokine has exclusively harmful effects. Any cytokine primarily has protective key func- 
tions in the symphony of immune responses and the organs' metabolism. Thus, any new cytokine antagonist will exert major side effects, as painfully experienced with TNF antagonists that were originally developed for septic patients but increased mortality in a dose-dependent fashion in these patients (IL-23). Moreover, cytokine antagonists, especially those that require few applications, cause long-lasting immune suppression. As IL-4 has a short half-life, is highly efficient in many inflammatory diseases and, importantly, exclusively interacts with pathogenic Th cells during the small time window of $\mathrm{T}$ cell activation, IL- 4 seems to be the most promising one among the potential candidate therapies. The mode of application, as parenteral protein, plasmid or orally available compound, remains a question of pharmacology.

\section{References}

1 Nestle FO, Kaplan DH, Barker J: Psoriasis. N Engl J Med 2009;361:496-509.

2 Luftl M, Degitz K, Plewig G, Rocken M: Psoralen bath plus UV-A therapy: possibilities and limitations. Arch Dermatol 1997;133: 1597-1603.

3 Saurat JH, Stingl G, Dubertret L, Papp K, Langley RG, Ortonne JP, Unnebrink K, Kaul M, Camez A: Efficacy and safety results from the randomized controlled comparative study of adalimumab vs. methotrexate vs. placebo in patients with psoriasis (CHAMPION). Br J Dermatol 2008; 158: 558-566.

4 Griffiths CE, Barker JN: Pathogenesis and clinical features of psoriasis. Lancet Oncol 2007;370:263-271.

5 Griffiths CE, Strober BE, van de Kerkhof P, Ho V, Fidelus-Gort R, Yeilding N, Guzzo C, Xia Y, Zhou B, Li S, Dooley LT, Goldstein $\mathrm{NH}$, Menter A: Comparison of ustekinumab and etanercept for moderate-to-severe psoriasis. N Engl J Med 2010;362:118-128.

6 Kneilling M, Mailhammer R, Hultner L, Schonberger T, Fuchs K, Schaller M, Bukala D, Massberg S, Sander CA, Braumuller H, Eichner M, Maier KL, Hallmann R, Pichler BJ, Haubner R, Gawaz M, Pfeffer K, Biedermann T, Rocken M: Direct crosstalk between mast cell-TNF and TNFR1-expressing endothelia mediates local tissue inflammation. Blood 2009;114:1696-1706.

7 Ghoreschi K, Mrowietz U, Rocken M: A molecule solves psoriasis? Systemic therapies for psoriasis inducing interleukin 4 and Th2 responses. J Mol Med 2003;81:471-480.

8 Altmeyer PJ, Matthes U, Pawlak F, et al: Antipsoriatic effect of fumaric acid derivatives: results of a multicenter double-blind study in 100 patients. J Am Acad Dermatol 1994;30: 977-981.
9 Krueger GG, Langley RG, Leonardi C, Yeilding N, Guzzo C, Wang Y, Dooley LT, Lebwohl M: A human interleukin-12/23 monoclonal antibody for the treatment of psoriasis. N Engl J Med 2007;356:580-592.

10 Heidenreich R, Rocken M, Ghoreschi K: Angiogenesis drives psoriasis pathogenesis. Int J Exp Pathol 2009;90:232-248.

11 Muller-Hermelink N, Braumuller H, Pichler B, Wieder T, Mailhammer R, Schaak K, Ghoreschi K, Yazdi A, Haubner R, Sander CA, Mocikat R, Schwaiger M, Forster I, Huss $\mathrm{R}$, Weber WA, Kneilling M, Rocken M: TNFR1 signaling and IFN- $\gamma$ signaling determine whether T cells induce tumor dormancy or promote multistage carcinogenesis. Cancer Cell 2008;13:507-518.

12 Biedermann T, Zimmermann S, Himmelrich H, Gumy A, Egeter O, Sakrauski AK, Seegmuller I, Voigt H, Launois P, Levine AD, Wagner H, Heeg K, Louis JA, Rocken M: IL-4 instructs TH1 responses and resistance to Leishmania major in susceptible BALB/c mice. Nat Immunol 2001;2:1054-1060.

13 Guenova E, Volz T, Sauer K, Kaesler S, Muller MR, Wolbing F, Chen K, Schwarzler C, Brossart P, Rocken M, Biedermann T: IL-4mediated fine tuning of IL-12p70 production by human DC. Eur J Immunol 2008; 38:3138-3149.

14 Ghoreschi K, Thomas P, Breit S, Dugas M, Mailhammer R, van Eden W, van der Zee R, Biedermann T, Prinz J, Mack M, Mrowietz U, Christophers E, Schlondorff D, Plewig G, Sander CA, Rocken M: Interleukin-4 therapy of psoriasis induces Th2 responses and improves human autoimmune disease. Nat Med 2003;9:40-46.

15 Martin R: Interleukin 4 treatment of psoriasis: are pleiotropic cytokines suitable therapies for autoimmune diseases? Trends Pharmacol Sci 2003;24:613-616.
16 Zhang Y, Li J, Liu CY, Zjou X, Qiu J, Zhan Y, Huang $N$, Chen $X$, Li X, Wang Y, Yang H, Chen X, Kan B, Mao Y, Deng H, Yang L, Wen Y, Zhao X, Wei YQ: A novel transdermal plasmid-dimethylsufoxide delivery technique for treatment of psoriasis. Dermatology DOI: 10.1159/000314154.

17 Detmar M, Brown LF, Claffey KP, Yeo KT, Kocher O, Jackman RW, Berse B, Dvorak HF: Overexpression of vascular permeability factor/vascular endothelial growth factor and its receptors in psoriasis. J Exp Med 1994;180:1141-1146.

18 Racke MK, Bonomo A, Scott DE, Cannella B, Levine A, Raine CS, Shevach EM, Rocken M: Cytokine-induced immune deviation as a therapy for inflammatory autoimmune disease. J Exp Med 1994;180:1961-1966.

19 Biedermann T, Mailhammer R, Mai A, Sander C, Ogilvie A, Brombacher F, Maier K, Levine AD, Rocken M: Reversal of established delayed type hypersensitivity reactions following therapy with IL- 4 or antigenspecific Th2 cells. Eur J Immunol 2001;31: 1582-1591.

20 Ren X, Li J, Zhou X, Luo X, Huang N, Wang $\mathrm{Y}$, Chen X, Wei Y: Recombinant murine interleukin 4 protein therapy for psoriasis in a transgenic VEGF mouse model. Dermatology 2009;219:232-238.

21 Leach MW, Rybak ME, Rosenblum IY: Safety evaluation of recombinant human interleukin-4. II. Clinical studies. Clin Immunol Immunopathol 1997;83:12-14.

22 Breit S, Steinhoff M, Blaser K, Heusser $\mathrm{CH}$, Sebald W, Levine AD, Rocken M: A strict requirement of interleukin-4 for interleukin-4 induction in antigen-stimulated human memory T cells. Eur J Immunol 1996;26: 1860-1865. 